\title{
Mutual Information and Nonadditive Entropies: A Method for Kaniadakis Entropy
}

\author{
Amelia Carolina Sparavigna ${ }^{1}$
}

${ }^{1}$ Department of Applied Science and Technology, Politecnico di Torino, Torino, Italy

\begin{abstract}
In [1], we have discussed the mutual information of two random variables and how it can be obtained from entropies. We considered the Shannon entropy and the nonadditive Tsallis entropy. Here, following the same approach used in the Tsallis case, we propose a method for discussing the mutual entropy of another nonadditive entropy, the Kaniadakis entropy.
\end{abstract}

Keywords: Mutual Information, Entropy, Tsallis Entropy, Kaniadakis Entropy, Generalized Additivity, Image Registration

\section{Introduction}

In the Ref.1, we are discussing mutual information of two random variables and how it can be calculated from entropies. The calculus is quite simple in the case of Shannon entropy, whereas, for the nonadditive Tsallis entropy, it requires some caution. Here, following the same approach used for the Tsallis entropy, we propose a method for discussing the case concerning another nonadditive entropy, the Kaniadakis entropy, and determine its mutual entropy.

Let us remember that Tsallis entropy is a generalization of the standard Boltzmann-Gibbs entropy, introduced in 1988 as a basis for generalizing the standard statistical mechanics [2], whereas the Kaniadakis entropy, also known as $\kappa$ entropy, emerged in the context of the special relativity $[3,4]$. Both entropies possess a generalized sum [5].

\section{Tsallis and Kaniadakis entropies}

The Tsallis entropy $\mathrm{T}$ is defined as:

$$
\mathrm{T}=\mathrm{T}_{\mathrm{q}}=\frac{1}{\mathrm{q}-1}\left(1-\sum_{\mathrm{i}} \mathrm{p}_{\mathrm{i}}^{\mathrm{q}}\right)
$$

In (1), $\mathrm{q}$ is the entropic index. $\left\{\mathrm{p}_{\mathrm{i}}\right\}$ are the probabilities where index $i$ is running from 1 to the total number of configurations. As q approaches 1, the Tsallis entropy becomes the Shannon entropy. The Tsallis entropy is linked to the Rényi entropy $\mathrm{R}$ [6], which is defined as:

$$
\mathrm{R}=\frac{1}{1-\mathrm{q}} \ln \sum_{\mathrm{i}} \mathrm{p}_{\mathrm{i}}^{\mathrm{q}}=\overline{\mathrm{T}}
$$

It is:

$$
\overline{\mathrm{T}}=\frac{\ln [1+(1-\mathrm{q}) \mathrm{T}]}{1-\mathrm{q}}
$$

If $\mathrm{X}, \mathrm{Y}$ are independent, for the Tsallis entropy we have a generalized additivity:

$$
\begin{aligned}
& \mathrm{T}(\mathrm{X}, \mathrm{Y}) \\
& =\mathrm{T}(\mathrm{X})+\mathrm{T}(\mathrm{Y})+(1-\mathrm{q}) \mathrm{T}(\mathrm{X}) \mathrm{T}(\mathrm{Y})
\end{aligned}
$$

$\mathrm{T}(\mathrm{X}, \mathrm{Y})$ is the entropy of the union of $\mathrm{X}$ and $\mathrm{Y}$. The Kaniadakis entropy $\mathrm{K}$ is also known as $\kappa$ entropy ( $\kappa$ is the entropic index). It is given by:

$$
\mathrm{K}=-\sum_{\mathrm{i}} \frac{\mathrm{p}_{\mathrm{i}}^{1+\kappa}-\mathrm{p}_{\mathrm{i}}^{1-\kappa}}{2 \kappa}
$$

Again, $\left\{p_{i}\right\}$ are the probabilities, and index $\mathrm{i}$ is running from 1 to the total number of configurations. However, in the case of Kaniadakis entropy, another function is necessary:

$$
\mathfrak{I}=\sum_{\mathrm{i}} \frac{\mathrm{p}_{\mathrm{i}}^{1+\kappa}+\mathrm{p}_{\mathrm{i}}^{1-\kappa}}{2}
$$

This article is published under the terms of the Creative Commons Attribution License 4.0 Author(s) retain the copyright of this article. Publication rights with Alkhaer Publications. Published at: http://www.ijsciences.com/pub/issue/2015-10/

DOI: $10.18483 /$ ijSci.845; Online ISSN: 2305-3925; Print ISSN: 2410-4477 
Let us note that: $\lim _{\kappa \rightarrow 0} \mathrm{~K}=\mathrm{S}_{\text {Shannon }}$ and $\lim _{\kappa \rightarrow 0} \mathfrak{I}=1$. For $X$ and $Y$ independent, the entropy of the union of $\mathrm{X}$ and $\mathrm{Y}$ is given by a generalized additivity:

$$
\mathrm{K}(\mathrm{X}, \mathrm{Y})=\mathrm{K}(\mathrm{X}) \mathfrak{I}(\mathrm{Y})+\mathrm{K}(\mathrm{Y}) \mathfrak{I}(\mathrm{X})
$$

Tsallis and Kaniadakis entropies are linked in the following manner:

$$
\mathrm{K}=\mathrm{K}_{\kappa}=\frac{\mathrm{T}_{1+\kappa}+\mathrm{T}_{1-\kappa}}{2}
$$

And:

$$
\begin{aligned}
& \mathrm{T}_{1+\kappa}=\mathrm{T}(\mathrm{q}=1+\kappa)=-\frac{1}{\kappa} \sum_{\mathrm{i}} \mathrm{p}_{\mathrm{i}}^{1+\kappa}+\frac{1}{\kappa} \\
& \mathrm{T}_{1-\kappa}=\mathrm{T}(\mathrm{q}=1-\kappa)=\frac{1}{\kappa} \sum_{\mathrm{i}} \mathrm{p}_{\mathrm{i}}^{1-\kappa}-\frac{1}{\kappa}
\end{aligned}
$$

Since Tsallis entropy $\mathrm{T}$ is linked to Rényi entropy, we can easily find a link of $\kappa$ - to Rényi entropy too.

\section{Mutual information for Kaniadakis entropy}

Let us shortly revise the discussion of mutual information given in [1], in order to define the symbols that we need to use for determining the mutual $\kappa$-entropy (when nonadditive entropies are involved, it is preferred to use the term "mutual entropy", instead of "mutual information" [7]).

The mutual information $\mathrm{I}(\mathrm{X} ; \mathrm{Y})$ of two random variables in subsystems $\mathrm{X}, \mathrm{Y}$ is providing a measure of the mutual dependence of the variables. Its physical meaning is the reduction of the uncertainty of $\mathrm{X}$ due to knowledge of $\mathrm{Y}$ (or vice versa). If $\mathrm{H}$ is the entropy: $H(X)=I(X ; X)$, so entropy is the "self- information". The mutual information is given by: $\mathrm{I}(\mathrm{X} ; \mathrm{Y})=\mathrm{H}(\mathrm{X})+\mathrm{H}(\mathrm{Y})-\mathrm{H}(\mathrm{X}, \mathrm{Y})$, with the following properties, $\mathrm{I}(\mathrm{X} ; \mathrm{Y})=\mathrm{I}(\mathrm{Y} ; \mathrm{X})$ and $\mathrm{I}(\mathrm{X} ; \mathrm{X})=\mathrm{H}(\mathrm{X})$. We have also $\mathrm{H}(\mathrm{Y} \mid \mathrm{H})$ and $\mathrm{H}(\mathrm{X}, \mathrm{Y})$, which are, respectively, the conditional entropy and the joint entropy for the combined system determined by $\mathrm{X}$ and $\mathrm{Y}$.

If $X, Y$ are independent, we have $I(X ; Y)=0$.

We can summarize symbols in the Venn diagram of Figure 1.

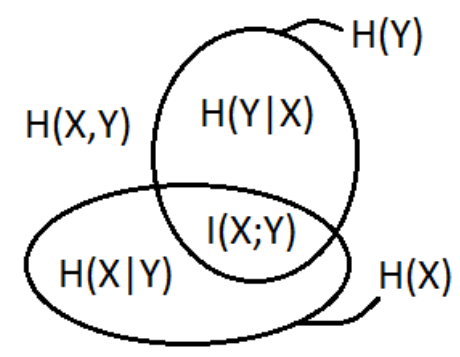

Figure 1: Venn diagram of mutual information $\mathrm{I}(\mathrm{X} ; \mathrm{Y})$, for $\mathrm{X}, \mathrm{Y}$ variables. The area contained by both circles is the joint entropy $\mathrm{H}(\mathrm{X}, \mathrm{Y})$.

For the Tsallis entropy, the conditional entropy is given as [8]:

$$
\begin{aligned}
& \mathrm{T}(\mathrm{X} \mid \mathrm{Y})=\frac{\mathrm{T}(\mathrm{X}, \mathrm{Y})-\mathrm{T}(\mathrm{Y})}{1+(1-\mathrm{q}) \mathrm{T}(\mathrm{Y})} \\
& \mathrm{T}(\mathrm{Y} \mid \mathrm{X})=\frac{\mathrm{T}(\mathrm{X}, \mathrm{Y})-\mathrm{T}(\mathrm{X})}{1+(1-\mathrm{q}) \mathrm{T}(\mathrm{X})}
\end{aligned}
$$

After the discussion in [1], we defined the mutual Tsallis entropy as:

$$
\mathrm{MT}(\mathrm{X} ; \mathrm{Y})=\mathrm{MT}(\mathrm{Y} ; \mathrm{X})=\frac{\mathrm{T}(\mathrm{X})+\mathrm{T}(\mathrm{Y})-\mathrm{T}(\mathrm{Y}, \mathrm{X})+(1-\mathrm{q}) \mathrm{T}(\mathrm{X}) \mathrm{T}(\mathrm{Y})}{1+(1-\mathrm{q})[\max \{\mathrm{T}(\mathrm{X}), \mathrm{T}(\mathrm{Y})\}]}
$$

This mutual entropy fulfils the requirements discussed in [1]. Let us use the $\kappa$-entropy instead of the Tsallis entropy. Let us define the Kaniadakis conditional entropies as [9]:

$$
\mathrm{K}(\mathrm{X} \mid \mathrm{Y})=\frac{\mathrm{K}(\mathrm{X}, \mathrm{Y})-\mathrm{K}(\mathrm{Y}) \mathfrak{I}(\mathrm{X})}{\mathfrak{I}(\mathrm{Y})} \quad ; \quad \mathrm{K}(\mathrm{Y} \mid \mathrm{X})=\frac{\mathrm{K}(\mathrm{X}, \mathrm{Y})-\mathrm{K}(\mathrm{X}) \mathfrak{I}(\mathrm{Y})}{\mathfrak{I}(\mathrm{X})}
$$

Let us consider, as we did in [1], a mutual $\kappa$-entropy as: 


$$
\begin{aligned}
& \mathrm{MK}^{*}(\mathrm{X} ; \mathrm{Y})=[\mathrm{K}(\mathrm{X})-\mathrm{K}(\mathrm{X} \mid \mathrm{Y})]=\frac{\mathfrak{I}(\mathrm{Y}) \mathrm{K}(\mathrm{X})-\mathrm{K}(\mathrm{X}, \mathrm{Y})+\mathrm{K}(\mathrm{Y}) \mathfrak{I}(\mathrm{X})}{\mathfrak{I}(\mathrm{Y})} \\
& \mathrm{MK}^{*}(\mathrm{Y} ; \mathrm{X})=[\mathrm{K}(\mathrm{Y})-\mathrm{K}(\mathrm{Y} \mid \mathrm{X})]=\frac{\mathfrak{I}(\mathrm{X}) \mathrm{K}(\mathrm{Y})-\mathrm{K}(\mathrm{X}, \mathrm{Y})+\mathrm{K}(\mathrm{X}) \mathfrak{I}(\mathrm{Y})}{\mathfrak{I}(\mathrm{X})}
\end{aligned}
$$

When $\mathrm{X}, \mathrm{Y}$ are independent, we see immediately that $\mathrm{MK}(\mathrm{X} ; \mathrm{Y})=\mathrm{MK}(\mathrm{Y} ; \mathrm{X})=0$.

Since we are searching for a "mutual entropy", equations (12a) and (12b) must give us the same information. To have this required symmetry, it is clear that we need a renormalization, as we did for the Tsallis entropy [1]. To find the proper renormalization of these formulas, let us try to fulfil some cases. For instance, we have the case when $\mathrm{Y}$ is completely dependent on $\mathrm{X}$ (in a Venn diagram, Figure 2 on the left, we have $\mathrm{Y}$ inside $\mathrm{X}$ ). In this case: $\mathrm{I}(\mathrm{X} ; \mathrm{Y})=\mathrm{H}(\mathrm{Y})$ and $\mathrm{H}(\mathrm{X}, \mathrm{Y})=\mathrm{H}(\mathrm{X})$.
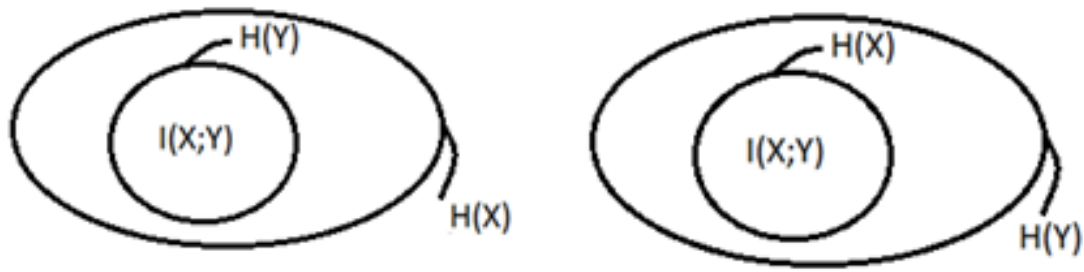

Figure 2: Venn diagram when $\mathrm{Y}$ is completely dependent on $\mathrm{X}$ (left) and when $\mathrm{X}$ is completely dependent on $\mathrm{Y}$ (right).

But if we use (12a) for instance, we find:

$$
\mathrm{MK}^{*}(\mathrm{X} ; \mathrm{Y})=\frac{\mathfrak{I}(\mathrm{Y}) \mathrm{K}(\mathrm{X})-\mathrm{K}(\mathrm{X})+\mathrm{K}(\mathrm{Y}) \mathfrak{I}(\mathrm{X})}{\mathfrak{I}(\mathrm{Y})} \neq \mathrm{K}(\mathrm{Y})
$$

Let us therefore renormalize this formula in the following manner:

$$
\begin{aligned}
& \operatorname{MK}^{* *}(\mathrm{X} ; \mathrm{Y}) \\
& =\frac{\mathrm{K}(\mathrm{X})(\mathfrak{I}(\mathrm{Y})-1)+\mathrm{K}(\mathrm{Y}) \mathfrak{I}(\mathrm{X})}{\mathfrak{I}(\mathrm{Y})} \frac{\mathrm{K}(\mathrm{Y}) \mathfrak{I}(\mathrm{Y})}{\mathrm{K}(\mathrm{X})(\mathfrak{I}(\mathrm{Y})-1)+\mathrm{K}(\mathrm{Y}) \mathfrak{I}(\mathrm{X})}=\mathrm{K}(\mathrm{Y})
\end{aligned}
$$

Here we have that $\mathrm{H}(\mathrm{X})$ is greater than $\mathrm{H}(\mathrm{Y})$. Let us write in $(13), \mathrm{K}(\mathrm{M})=\mathrm{K}(\mathrm{X})$ and $\mathrm{K}(\mathrm{m})=\mathrm{K}(\mathrm{Y})$, with $\mathrm{K}(\mathrm{M})$ indicating the larger entropy and $\mathrm{K}(\mathrm{m})$ the smaller entropy:

$$
\begin{aligned}
& \mathrm{MK}^{* *}(\mathrm{X} ; \mathrm{Y}) \\
& =\frac{\mathrm{K}(\mathrm{M}) \mathfrak{I}(\mathrm{m})-\mathrm{K}(\mathrm{M})+\mathrm{K}(\mathrm{m}) \mathfrak{I}(\mathrm{M})}{\mathfrak{I}(\mathrm{m})} \frac{\mathrm{K}(\mathrm{m}) \mathfrak{I}(\mathrm{m})}{\mathrm{K}(\mathrm{M})(\mathfrak{I}(\mathrm{m})-1)+\mathrm{K}(\mathrm{m}) \mathfrak{I}(\mathrm{M})}=\mathrm{K}(\mathrm{Y})
\end{aligned}
$$

In the case of Figure 2 on the left, from (14) we have $M K(X ; Y)=K(Y)$. However, we can have also the case when $\mathrm{X}$ is completely dependent on $\mathrm{Y}$ (in a Venn diagram, we have $\mathrm{X}$ inside $\mathrm{Y}$; see Figure 2 on the right). In this case: $\mathrm{I}(\mathrm{X} ; \mathrm{Y})=\mathrm{H}(\mathrm{X})$ and $\mathrm{H}(\mathrm{X}, \mathrm{Y})=\mathrm{H}(\mathrm{Y})$. If we use $(14)$, with $\mathrm{K}(\mathrm{M})=\mathrm{K}(\mathrm{Y})$ and $\mathrm{K}(\mathrm{m})=\mathrm{K}(\mathrm{X})$, we have that $\mathrm{MK}(\mathrm{X} ; \mathrm{Y})=\mathrm{K}(\mathrm{X})$, as expected.

After this discussion then, we propose to define the mutual $\kappa$-entropy in the following manner: 


$$
\begin{gathered}
\mathrm{MK}(\mathrm{X} ; \mathrm{Y})=\frac{\mathfrak{I}(\mathrm{Y}) \mathrm{K}(\mathrm{X})-\mathrm{K}(\mathrm{X}, \mathrm{Y})+\mathrm{K}(\mathrm{Y}) \mathfrak{I}(\mathrm{X})}{\mathfrak{I}(\mathrm{m})} \frac{\mathrm{K}(\mathrm{m}) \mathfrak{I}(\mathrm{m})}{\mathrm{K}(\mathrm{M})(\mathfrak{I}(\mathrm{m})-1)+\mathrm{K}(\mathrm{m}) \mathfrak{I}(\mathrm{M})} \\
\mathrm{K}(\mathrm{M})=[\max \{\mathrm{K}(\mathrm{X}), \mathrm{K}(\mathrm{Y})\}] ; \mathrm{K}(\mathrm{m})=[\min \{\mathrm{K}(\mathrm{X}), \mathrm{K}(\mathrm{Y})\}]
\end{gathered}
$$

Let us note that, when $\kappa$ approaches zero, we have: $\mathrm{MK}(\mathrm{X} ; \mathrm{Y})=\mathrm{S}(\mathrm{X})-\mathrm{S}(\mathrm{X}, \mathrm{Y})+\mathrm{S}(\mathrm{Y})=\mathrm{I}(\mathrm{X} ; \mathrm{Y})$. $\mathrm{S}$ are the Shannon entropies. From (15), it is clear the relevant role of the auxiliary function $\mathfrak{J}$, which is necessary for the Kaniadakis generalized additivity. Further studies are in progress for a more rigorous approach to conditional and mutual entropy and for evaluating the conditional Kaniadakis entropies for multivariate problems.

\section{References}

1) A.C. Sparavigna (2015). Mutual Information and Nonadditive Entropies: The Case of Tsallis Entropy, Int. J. Sci. in print.

2) C. Tsallis (1988). Possible Generalization of BoltzmannGibbs Statistics, Journal of Statistical Physics 52:479. DOI:10.1007/BF01016429
3) G. Kaniadakis (2002). Statistical mechanics in the context of special relativity, Phys. Rev. E 66: 056125. DOI: 10.1103/physreve.66.056125

4) G. Kaniadakis (2013). Theoretical foundations and mathematical formalism of the power-law tailed statistical distributions, Entropy 15:3983. DOI: 10.3390/e15103983

5) AC. Sparavigna (2015). On the Generalized Additivity of Kaniadakis Entropy, Int. J. Sci., 2015, 4(2):44; DOI: 10.18483/ijSci.627

6) A. Rényi (1960). On Measures of Information and Entropy, Proceedings of the Fourth Berkeley Symposium on Mathematics, Statistics and Probability, pp. 547-561.

7) S. Furuichi (2006). Information Theoretical Properties of Tsallis Entropies, J. Math. Phys. 47:023302. DOI:10.1063/1.2165744

8) S. Abe, A.K. Rajagopal (2000). Nonadditive Conditional Entropy and its Significance for Local Realism, arXiv:quant-ph/0001085, 24 Jan 2000.

9) A.C. Sparavigna (2015). Conditional Kaniadakis Entropy: a Preliminary Discussion. PHILICA.COM Article number 524. 